\title{
Article \\ RNA-Seq Analysis on the Microbiota Associated with the White Shrimp (Litopenaeus vannamei) in Different Stages of Development
}

Raúl Enrique Valle-Gough ${ }^{1}$, Blancka Yesenia Samaniego-Gámez ${ }^{2} \mathbb{D}$, Javier Eduardo Apodaca-Hernández ${ }^{3}$,
Francisco Xavier Chiappa-Carrara ${ }^{4}$ (D), Mauricio Rodríguez-Dorantes ${ }^{5}$ and María Leticia Arena-Ortiz ${ }^{1, *}(\mathbb{D})$

check for updates

Citation: Valle-Gough, R.E.; Samaniego-Gámez, B.Y; Apodaca-Hernández, J.E.;

Chiappa-Carrara, F.X.;

Rodríguez-Dorantes, M.; Arena-Ortiz, M.L. RNA-Seq Analysis on the Microbiota Associated with the White Shrimp (Litopenaeus vannamei) in Different Stages of Development. Appl. Sci. 2022, 12, 2483. https:// doi.org/10.3390/app12052483

Academic Editors: Tiago Verdelhos and Ana Cristina Rocha

Received: 22 January 2022

Accepted: 24 February 2022

Published: 27 February 2022

Publisher's Note: MDPI stays neutral with regard to jurisdictional claims in published maps and institutional affiliations.

Copyright: (C) 2022 by the authors. Licensee MDPI, Basel, Switzerland. This article is an open access article distributed under the terms and conditions of the Creative Commons Attribution (CC BY) license (https:// creativecommons.org/licenses/by/ $4.0 /)$.
1 Ecogenomics Laboratory, Autonomous National University of Mexico (UNAM), Sierra Papacal Road, Km. 5.5, Chuburna Port. Sierra Papacal, Merida 97302, Mexico; revg8983@gmail.com

2 Institute of Agricultural Sciences, Autonomous University of Baja California, Carretera Blvd., Delta s/n Ejido Nuevo León, Valle de Mexicali, Mexicali 21705, Mexico; samaniego.blancka@uabc.edu.mx

3 Laboratory of Genomic Computing, Genomic Libraries (Bibliotecas Genómicas), 3 St, \# 404 by 24 a. Bugambilias de Chuburna, Merida 97205, Mexico; javier.apodaca@gmail.com

4 Conservation Biology Laboratory, Autonomous National University of Mexico (UNAM), Sierra Papacal Road, Km. 5.5, Chuburna Port. Sierra Papacal, Merida 97302, Mexico; xcc@ciencias.unam.mx

5 Oncogenomic Consortium, National Institute of Genomic Medicine (INMEGEN), South Periphery 4809, Arenal Tepepan Tlapan, CDMX 14610, Mexico; mrodriguez@inmegen.gob.mx

* Correspondence: leticia.arena@ciencias.unam.mx

Featured Application: The potential use of these types of studies lies in the functional characterization of the microbiome with a given nutritional management under culture conditions. The present study could be used for the selection of molecular markers for the assessment of several parameters associated with the nutrition, stress response and health status in each stage of development of this species during its culture.

Abstract: White leg shrimp (Litopenaeus vannamei) is a widely cultured species along the Pacific coast and is one of the most important crustaceans in world aquaculture. The microbiome composition of L. vannamei has been previously studied in different developmental stages, but there is limited information regarding the functional role of the microbiome during the development of L. vannamei. In this study the metatranscriptome in different developmental stages of L. vannamei (larvae, juvenile and adult) were generated using next generation sequencing techniques. The bacterial phyla found throughout all the stages of development belonged to the Proteobacteria, Firmicutes and Actinobacteria, these bacterial phyla are present in the digestive tract and are capable of producing several hydrolytic enzymes, which agrees with high representation of the primary metabolism and energy production, in both host and the microbiome. In this sense, functional changes were observed as the development progressed, in both host and the microbiome, in stages of larvae the most represented metabolic functions were associated with biomass production; while in juvenile and adult stages a higher proportion of metabolic functions associated to biotic and abiotic stress in L. vannamei and the microbiome were shown. This study provides evidence of the interaction of the microbiome with $L$. vannamei, and how the stage of development and the culture conditions of this species influences the gene expression and the microbiome composition, which suggests a complex metabolic network present throughout the life cycle of L. vannamei.

Keywords: transcriptomics; RNA-Seq; metatranscriptomics; functional analysis; development; microbiome; NGS

\section{Introduction}

The white shrimp (Litopenaeus vannamei) is a widely cultured crustacean in the Pacific Ocean and is considered one of the dominant shellfish in world aquaculture with a global 
production of 300 metric tons [1-7]. The culture of Litopenaeus vannamei (L. vannamei) is widely extended due its adaptability to different environmental conditions. Currently, several factors could threaten the production of L. vannamei: (1) the culture expansion has a negative impact on the environment, caused by farm effluents, (2) the high density during production has increased disease outbreaks in ponds and (3) emergence of antibiotic resistant pathogens given the continual use of these compounds during the culture $[3,4,8,9]$.

One of the strategies used to improve the production in L. vannamei, is microbiome manipulation through nutritional management or by the inclusion of probiotics. In this sense, the microorganisms that inhabit the host are capable of producing digestible molecules that improve growth, health status, life-span and the resistance to biotic and abiotic factors in different of shellfish species [2,9-12]. The digestive functions in several species of decapods are performed by the hepatopancreas; in this organ the interaction among bacteria and the host allows the absorption of different types of substrates [3,4,10,12-14].

The function of the microbiome has been largely unknown, recent advances using next generation sequencing techniques along with function prediction software have allowed visualization of some of the complex trophic networks between the host organism and the microbiome [15-18]. Previous studies of Peneids have focused on the microbiome composition in different stages of development, where the phyla Proteobacteria, Bacteroidetes, Firmicutes and Actinobacteria were in high abundance throughout all the developmental stages of L. vannamei $[2-4,10,19]$. In this sense, changes in the microbiome structure have been reported during L. vannamei culture, where the presence of the Comamonadaceae family appeared when live feed was provided [2].

Other type of studies in L. vannamei have focused on the influence of probiotics in growth variables [20,21], physiological response [22], nutritional aspects [23], in the transcript profile in different tissues and in the response to different viral pathogens $[4,6,24]$. All the aforementioned studies were able to identify how the development, health status and the culture conditions influence the microbiome composition and the gene expression in L. vannamei. Although the information regarding the microbiome function in L. vannamei is reduced, there is only one report on this species which was performed in the hepatopancreas of adult individuals of L. vannamei in culture conditions [25] where the presence of host and microbiome transcripts were related to the nutrient uptake and the response to abiotic and biotic stress.

Given that the microbiome is highly dynamic, it is important to elucidate its role during different developmental stages in L. vannamei, in order to identify how the conditions of each stage of development shapes the microbial communities and how these communities interact with host transcripts. The objective of the present study was to determine the role of the metabolically active bacterial communities during the development of L. vannamei in larval, juvenile and adult stages. This study represents the first report regarding the functional role of the microorganisms and the possible interactions during the development of L. vannamei.

\section{Materials and Methods}

\subsection{Biological Samples and Culture Conditions}

White shrimp samples identified as L. vannamei were collected in culture ponds during August 2016 in the facilities of Aquapacific (Mazatlan, Sinaloa, Mexico).

Larvae: these stages corresponded to twelve-day-old postlarvae, the individuals were collected in culture tanks at $32{ }^{\circ} \mathrm{C}$, with a salinity of $3 \%(w / v)$ and supplemented with a commercial feeding formula which consisted of: $50 \%$ crude protein, $15 \%$ crude fat, $7.5 \%$ ash, $1 \%$ crude fiber and $0.9 \%$ phosphorous. Other components supplemented in the formula by the manufacturer include: proteins (algae, animal, plant), oils (fish, vegetables), vegetable starches, minerals, pigments, yeast, carotenoids, vitamins and antioxidants.

Juvenile: these stages corresponded to two-month-old individuals, which were grown at $29{ }^{\circ} \mathrm{C}$ with a salinity of $3 \%(w / v)$, and collected in pre-molting stages. The commercial feeding formula in this stage consisted of $40 \%$ protein, $9 \%$ fat, $13 \%$ ash, $3 \%$ fiber and 
$1.1 \%$ phosphorous. Other components supplemented in the formula by the manufacturer include: protein (algae, plant), animal protein (Artemia), oils (fish, vegetables), vegetable starches, minerals, pigments, yeast, carotenoids, vitamins and antioxidants.

Adult: these stages included four-month-old individuals, which were collected in culture ponds at $32{ }^{\circ} \mathrm{C}$ with a salinity of $3 \%(w / v)$ in post-molting stages. The commercial feeding formula at this stage of development consisted of $35 \%$ crude protein, $7 \%$ crude fat (fish and vegetable), $2 \%$ crude fiber and $13 \%$ ash. Other components supplemented in the formula by the manufacturer include: marine proteins, plant proteins (grains and grain by-products), vitamins, minerals, yeast and yeast by-products.

A total of 10 individuals of the larval stages of L. vannamei were placed in sterile gauze, placed in plastic bags and stored in dry ice. In the case of juvenile and adult samples, a total of 20 individuals were placed individually in sterile gauze, placed in plastic bags and stored in dry ice. The samples were transported to the Laboratory of Ecogenomics, UNAM, where the samples were stored at $-80^{\circ} \mathrm{C}$ until further use.

\subsection{Total RNA Extraction of L. vannamei in Different Developmental Stages}

Larvae: a total of 10 individuals were placed in ice-cold nuclease-free tubes $(1.5 \mathrm{~mL})$ (Eppendorf, Hamburg, Germany) with $750 \mu \mathrm{L}$ of TRI-Reagent (Zymo Search, Irvine, CA, USA), total RNA was extracted according to the Chomczinsky and Sacchi [26] protocol and the RNA was further purified with sodium acetate precipitation [27].

Juvenile and adults: a total of 10 individuals of each stage of development were decapitated and sectioned in RNase-free conditions, the hepatopancreas of each individual was removed and sectioned in $200 \mathrm{mg}$ fragments. These fragments were transferred to ice-cold nuclease-free tubes $(1.5 \mathrm{~mL})$ (Eppendorf) with $750 \mu \mathrm{L}$ of TRI-Reagent (Zymo Search), total RNA was extracted according to Chomczinsky and Sacchi [26] with minor modifications (two additional extractions with chloroform and RNA purification with by sodium acetate precipitation [27]).

The samples were treated with DNase I with the DNA-Free kit (Ambion, Austin, TX, USA) following the manufacturer's instructions. The RNA was visualized in agarose gels (1\%) stained with SYBRSAFE (BIORAD, Hercules, CA, USA) under RNase-free conditions. The RNA integrity number (RIN) of each sample was assessed in a Bioanalyzer (BioAnalyzer 2100, Agilent, Santa Clara, CA, USA); the samples with an RIN value $>8.0$ were selected.

The ribosomal RNA depletion of the samples was performed for eukaryotes with the Low Input RiboMinus Eukaryote System V2 (Ambion) for the eukaryotic samples according to the manufacturer's instructions. In the case of prokaryotes the ribosomal RNA was depleted with the RiboMinus Transcriptome Isolation Kit, Bacteria (Invitrogen, Waltham, MA, USA) according to the manufacturer's instructions. The ribosomal RNA depleted samples of each stage of development were pooled together according to their developmental stage, two biological replicates and technical triplicates of each sample were sent for sequencing.

\subsection{RNA-Seq of L. vannamei}

The ribosomal RNA depleted samples were sent to the National Institute of Genomic Medicine (INMEGEN, Mexico City, Mexico) for library construction and sequencing. Library construction was performed with the TruSeq Stranded Total RNA Library Prep (Illumina, San Diego, CA, USA) according to the manufacturer's instructions. The sequencing was performed in the Illumina NextSeq500 system with a pair-ended (PE, $2 \times 75 \mathrm{pb}$ ), $50 \mathrm{~Gb}$ output and with 50 million reads per sample, with three technical replicates and biological duplicates of each stage of development.

Quality control of the obtained sequences was performed with FASTQC software (http://www.bioinformatics.babraham.ac.uk/projects/fastqc/, 8 December 2021). The sequencing adapters were removed with the Trim Galore module in the Galaxy platform (https:/ / usegalaxy.org/, 8 December 2021) with a PHRED = 20 value and the Illumina- 
NextSeq-V3.0 adapter list was used. The adapter-free sequences were processed for the removal of low-quality reads in the Trimmomatic software (v 0.36) (http:/ / www.usadellab. org $/ \mathrm{cms}$ /index.php?page=trimmomatic, 8 December 2021) with a PHRED = 33 value, a minimal read length of $31 \mathrm{bp}$ and a sliding window of 5:30.

The remaining reads, free of ambiguous bases, were concatenated and assembled with TrinityRNASeqv2.2.0 software (https:/ / github.com/trinityrnaseq/trinityrnaseq, 8 December 2021) in fastq format with $\mathrm{K}$-mer size of $31 \mathrm{bp}$ with a minimal contiguous sequence (contig) of $200 \mathrm{pb}$. The resulting file was mapped with Bowtie1 with the pair-end option and the abundance of the mapped transcripts was estimated using the RSEM method.

\subsection{Taxonomic and Functional Analysis in L. vannamei}

The assembled sequences in fasta format were introduced in the Galaxy platform for taxonomic representation with the Kraken algorithm with the bacteria dataset, the results were exported in tabular format.

The assembled sequences of each stage of development were introduced in the MG-RAST (MetaGenomic Rapid Annotation using Subsystem Technology) platform [28] (https://www.mg-rast.org/, 8 December 2021) for functional analysis of orthologous groups (COG), subsystem database (SEED) and the Kyoto Encyclopedia of Genes and Genomes (KEGG) with a minimal cut-off value of $\mathrm{E}=1 \times 10^{-5}$ in both eukaryotic and prokaryotic sequences.

The metabolic pathway analysis was performed with the KEGG orthology (KO) numbers and enzyme codes (EC) obtained from the KEGG, SEED and COG databases. The KO and EC were visualized in IPATH3.0 [29] (https:/ / pathways.embl.de/ 8 December 2021) where eukaryote and prokaryote main metabolic modules were visualized in each stage of development along with the overlapping functions, using the ID overlap analysis, in the overall metabolic pathways.

\section{Results}

A total of 19,030 assembled contigs with a PHRED $=30$ value were obtained in larvae, with a mean contig length of $304 \mathrm{bp}$. The MG-RAST software identified a total of 15,143 protein sequences with predicted functions, of which 4089 were proteins with known functions and were classified into 2427 functional categories.

In juvenile samples, a total of 47,336 assembled contigs with a mean contig length of $555 \mathrm{bp}$ with a PHRED $=30$ value were obtained. In this stage MG-RAST identified a total of 26,803 predicted proteins, of which 7223 had known functions and these were classified into 4203 functional categories.

Adult stages showed a total of 47,742 with assembled contigs with a mean contig length of $614 \mathrm{bp}$ with a PHRED $=30$ value. A total of 25,170 predicted proteins were identified in this stage by MG-RAST, of which 6525 proteins had known functions and were classified into 3819 functional categories.

\subsection{Taxonomic Representation of the Microbiome in Different Developmental Stages of L. vannamei}

During the development of $L$. vannamei gradual increases in the metabolically active taxa were observed, and fluctuations in the abundance of different bacterial taxa were also identified at phylum, class, order and family levels.

The main bacterial phyla present in larvae (18 phyla), juvenile (24 phyla) and adult (26 phyla), were: Proteobacteria, Bacteroidetes, Firmicutes and Actinobacteria (Figure 1). Which represented $85 \%$ of the total reads in larvae, while in juvenile and adult represented $78 \%$ and $76 \%$, respectively. Several bacterial phyla were represented in higher proportions at a particular stage of development, such as: Larvae (Planctomycetes, Chlorobi), juvenile (Cyanobacteria, Tenericutes, Spirochaetes, Verrucomicrobia) and adult (Euryarchaeota, Fusobacteria). 


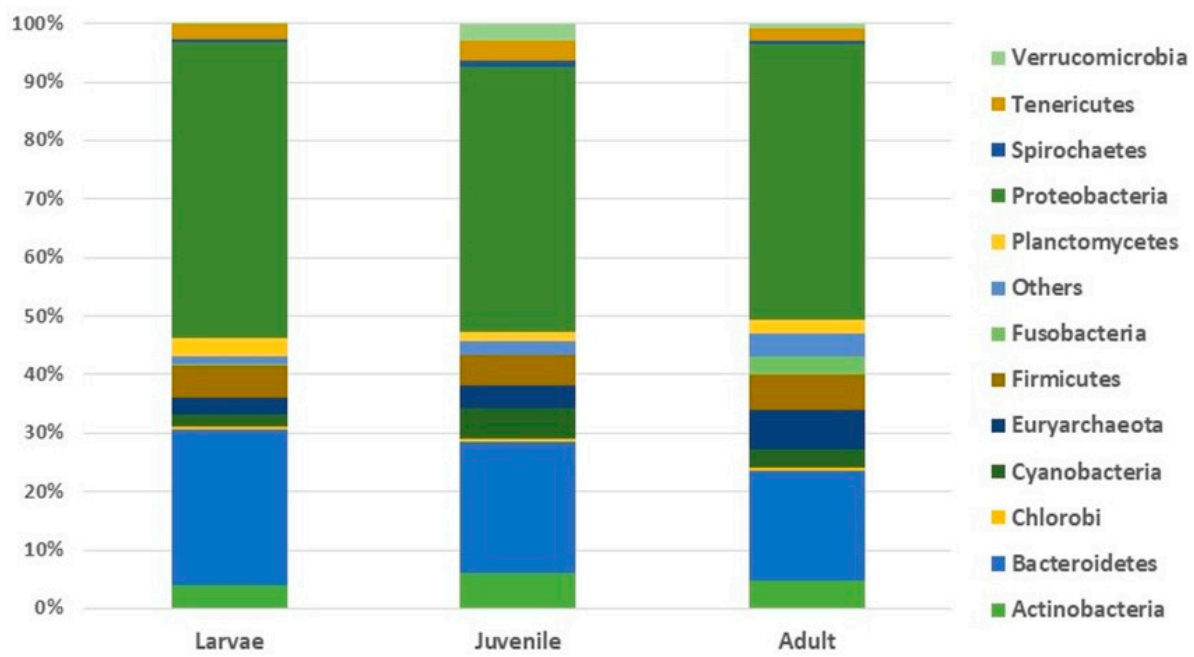

Figure 1. Taxonomical composition at phylum level of the L. vannamei microbiome in different stages of development.

The class level composition in larvae (28 classes), juvenile (36 classes) and adult (38 classes), showed that the Gammaproteobacteria, Flavobacteria, Alphaproteobacteria, Sphingobacteria and Cytophaga (Figure 2) were highly represented throughout all the developmental stages in L. vannamei. Which accounted the $68 \%$ of the total reads in larvae, $55 \%$ in juvenile and $54 \%$ in adult. Other bacterial classes were observed in high proportion at particular stages of development in larvae (Planctomycetia), juvenile (Actinobacteria, Mollicutes, Deltaproteobacteria, Betaproteobacteria) and adult (Bacilli, Epsilonproteobacteria, Fusobacteria, Methanococci).

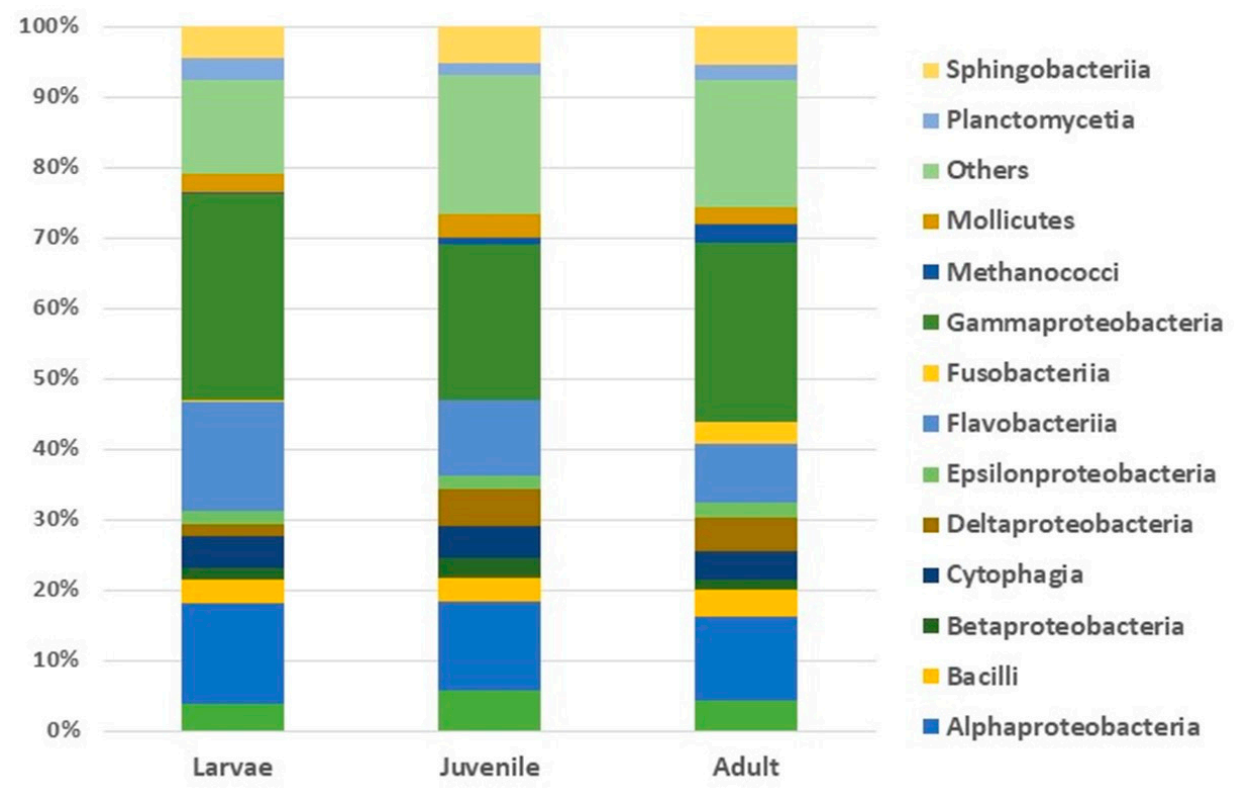

Figure 2. Taxonomical composition at class level of the L. vannamei microbiome in different stages of development.

The most represented bacterial orders present in larvae ( 72 orders), juvenile ( 88 orders) and adults ( 80 orders) belonged to Flavobacteriales, Rhodobacterales, Alteromonadales and Sphingobacteriales (Figure 3). The aforementioned orders represented $41 \%$ of the total reads in larvae, $29 \%$ in juvenile and $25 \%$ in adults. Other important orders were found at high proportions in particular stages of development in larvae (Planctomycetales), juvenile ( $\mathrm{Cy}$ tophagales, Oceanospirillales, Enterobacteriales, Burkholderiales, Bacillales) and adult (Vibrionales, Fusobacterales, Methanococcales). 


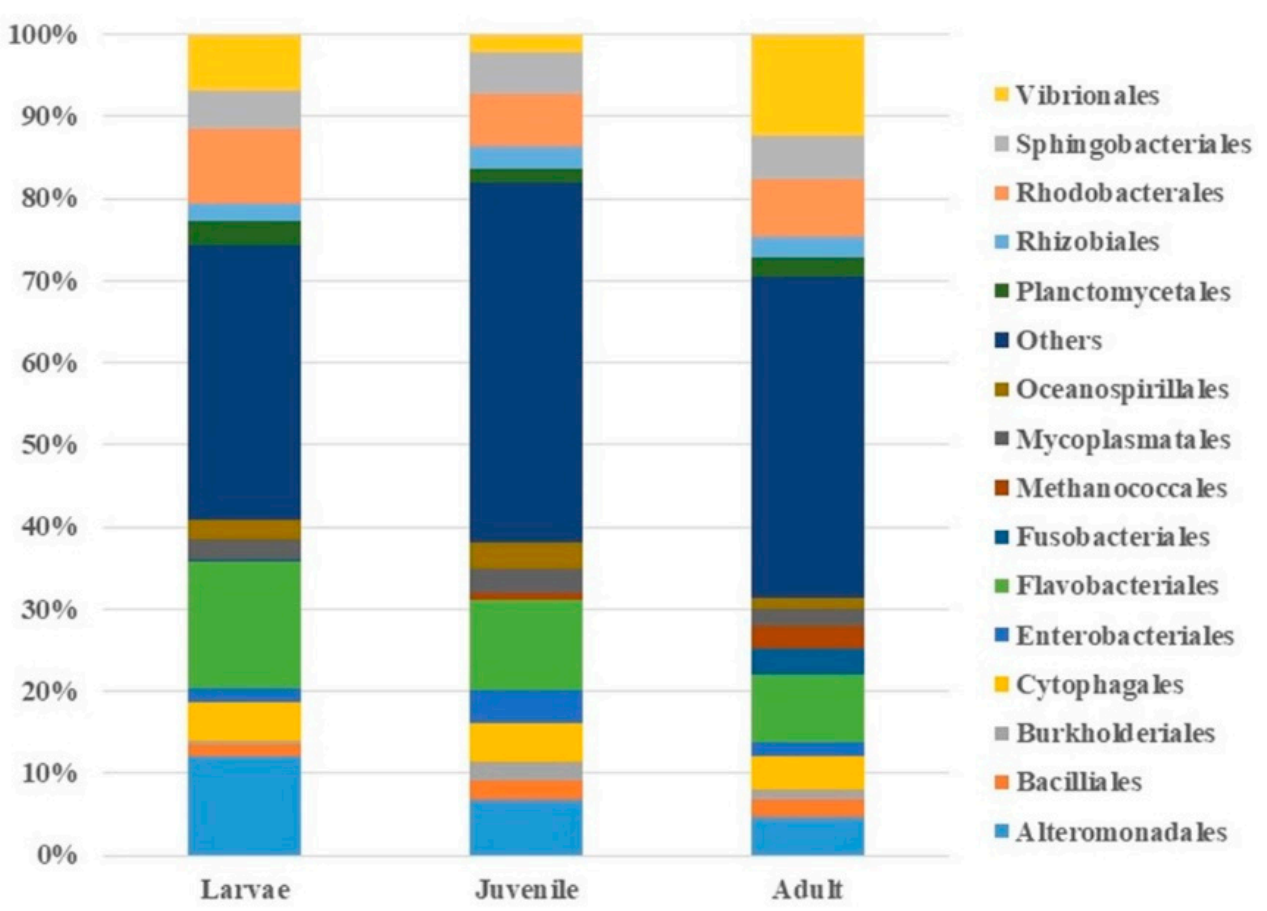

Figure 3. Taxonomical composition at order level of the L. vannamei microbiome in different stages of development.

The family level composition consisted in: larvae (109 families), juvenile (145 families) and adult (128 families) in which the Flavobacteriaceae, Rhodobacteraceae and Vibrionaceae represented $29 \%$ of the total reads in larvae, $16 \%$ in juvenile and $25 \%$ in adult (Figure 4 ). Other highly represented bacterial families were found in a particular stage of development such as larvae (Pseudoalteromonadaceae, Alteromonadaceae, Saprospiraceae, Cyclobacteriaceae, Planctomycetaceae, Shewanellaceae), juvenile (Mycoplasmataceae, Enterobacteriaceae, Cytophagaceae, Alcanivoraceae, Akkermansiaceae) and adult (Helicobacteraceae, Bacillaceae, Methanococcaceae, Fusobacteriaceae, Streptomycetaceae).

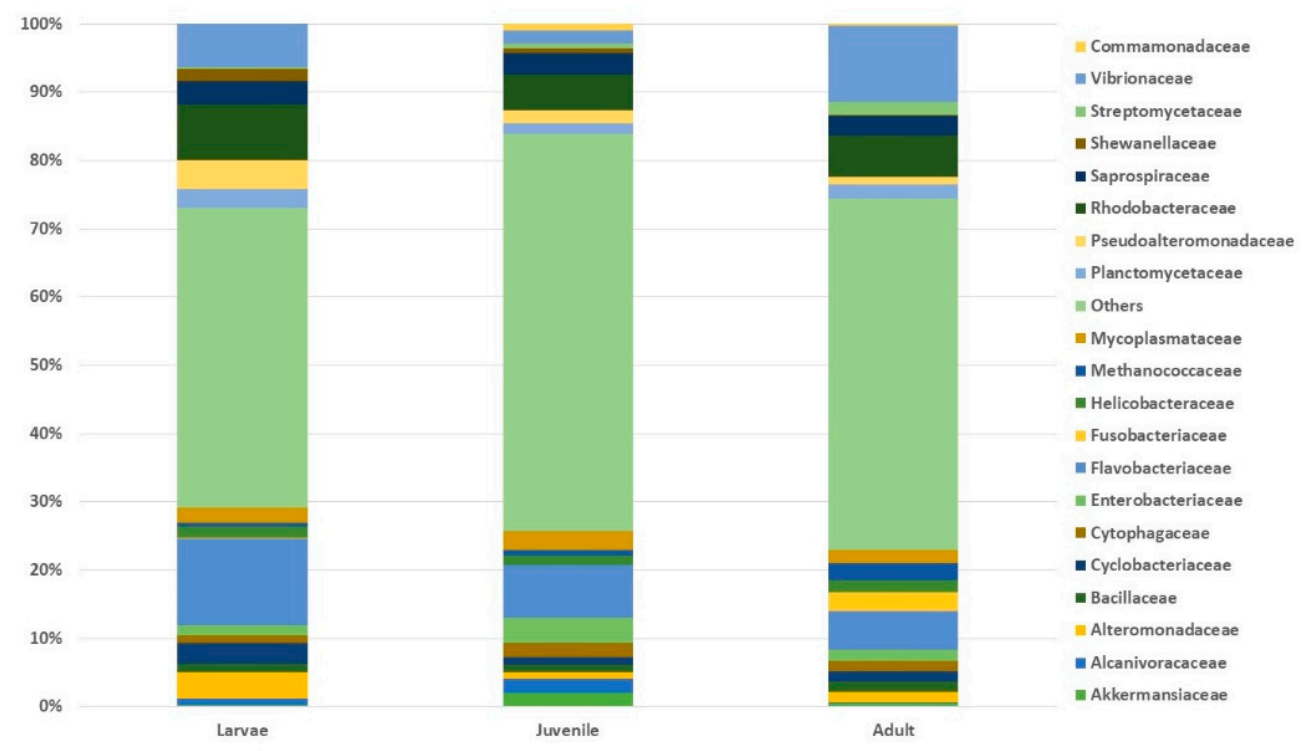

Figure 4. Taxonomical composition at family level of the L. vannamei microbiome in different stages of development. 


\subsection{Functional Representation of L. vannamei in Different Stages of Development}

The functional representation of the microbiome in L. vannamei was analyzed using the COG database (Figure 5a). This database showed that a high proportion of transcripts were grouped in the "Metabolism" classification, where the juvenile stages showed a higher proportion of these transcripts (77\%). Other highly represented groups were those associated with "Information Storage and Processing" in larvae (49\%) and adult (37\%) stages.

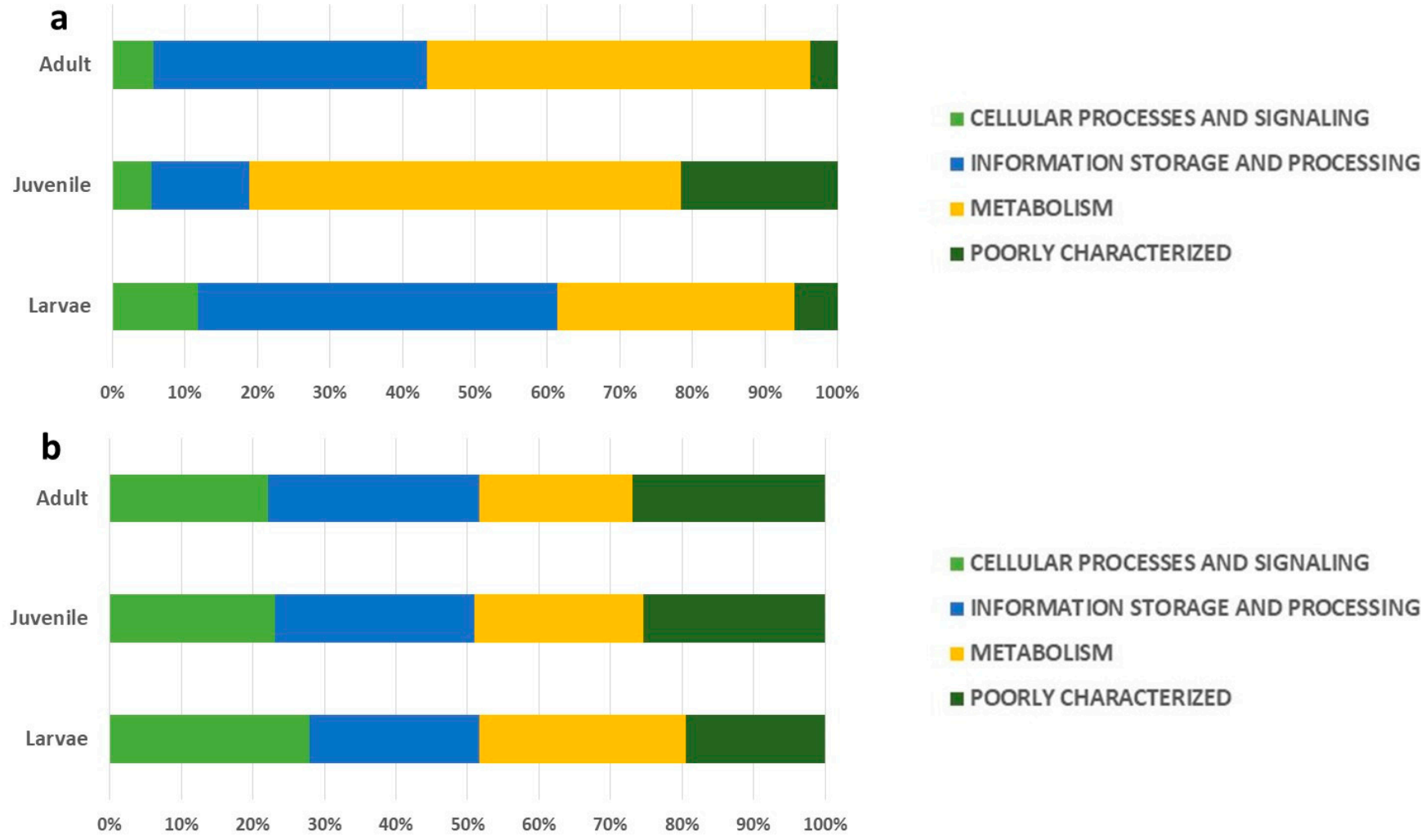

Figure 5. Clustered analysis of orthologous groups in different developmental stages of L. vannamei, (a) prokaryotic orthologous groups, (b) eukaryotic orthologous groups.

In the COG database a gradual increase of the host transcripts (Figure 5b) associated with "Information Storage and Processing" was observed. The "Cellular Processes and Signaling" showed a decreasing pattern in the proportion of transcripts as the development advanced, where the larval stages ( $28 \%$ ) showed the highest proportion of transcripts of this orthologous cluster.

The bacterial transcripts associated with the "Metabolism" cluster increased as the development of L. vannamei progressed, while in the host an opposite behavior could be noticed. In the case of "Information Storage and Processing" the adult stages showed a high proportion of transcripts in both the host and the microbiome.

The subsystem classification database (SEED) showed that the processes related to the metabolism of carbohydrates and proteins were highly represented throughout all the developmental stages in the microbiome (40-52\%) (Figure 6). The most represented subsystems in the microbiome were related to the metabolism of proteins in larvae and adult individuals; in juvenile stages the most represented subsystems were related to the metabolism of lipids and amino acids (Figure 6). Furthermore, during larvae (3.1\%), juvenile (2.1\%) and adult $(1.4 \%)$ stages, the presence of the microbiome subsystems related to "Virulence, Disease and Defense" showed a decreasing tendency as the development progressed. 


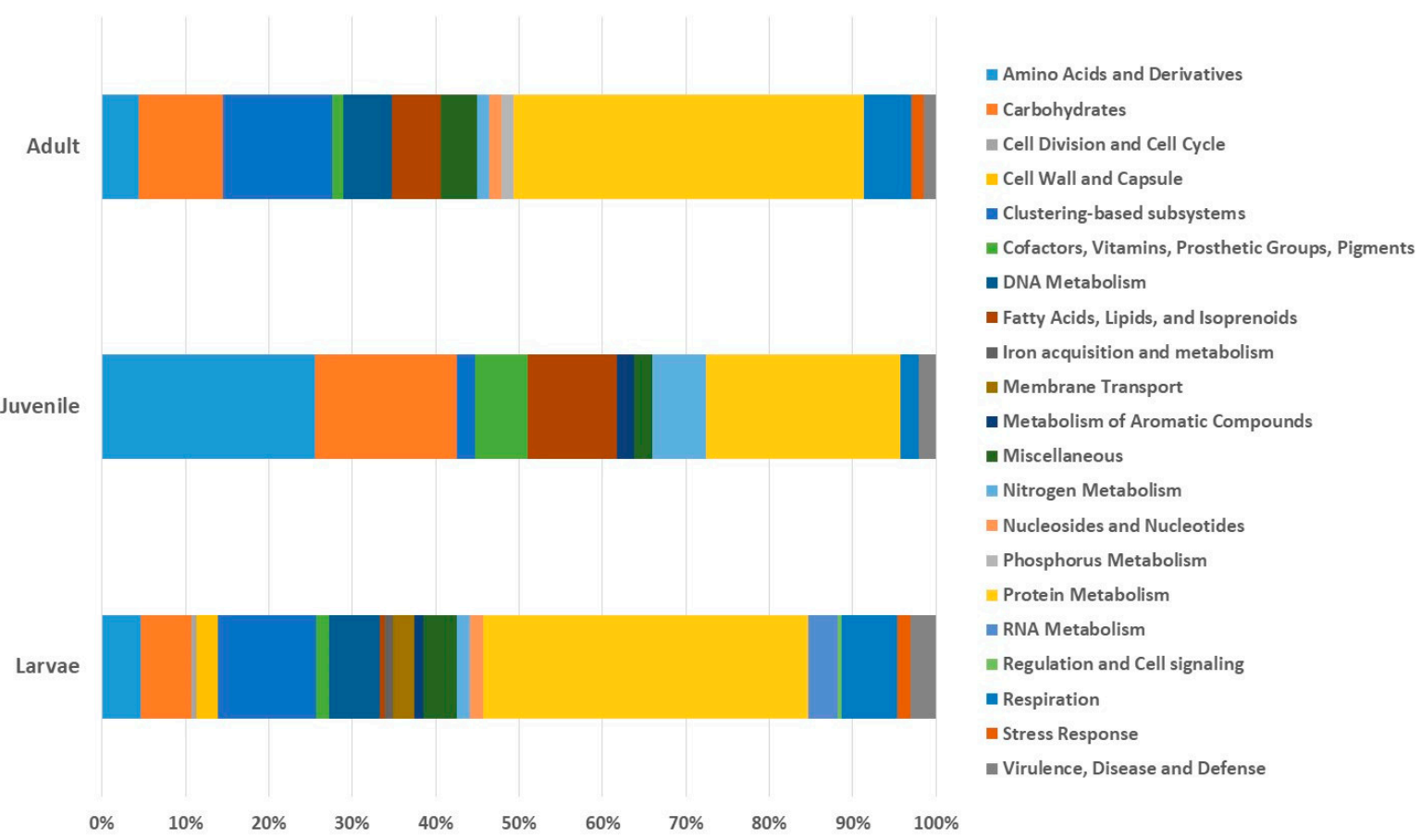

Figure 6. Functional classification based on subsystems in the microbiome during different stages of development in L. vannamei.

The subsystem representation in the host (Figure 7) showed that the protein (25-41\%) and carbohydrate $(8-14 \%)$ metabolism was highly represented throughout the development of L. vannamei. The subsystems associated with "Fatty acids, Lipids and Isoprenoids" showed a decreasing tendency as the development progressed, while in juvenile and adult stages the "Stress response" and "RNA Metabolism" subsystems showed an increasing tendency.



Figure 7. Functional classification based on subsystems during different stages of development in L. vannamei.

\subsection{Microbiome Metabolic Analysis during the Development of L. vannamei}

Several functions in both the host and the microbiome belonged to primary metabolic processes (Supplementary Figures S1 and S2) that were present throughout the development of L. vannamei. These pathways were associated with several enzymatic modules, such 
as: energy production, fatty acid elongation, protein modification, translation, secondary metabolism, nucleotide and carbohydrate metabolism. Other modules were only observed in the host, such as defense mechanisms, this cluster showed an increasing tendency as the development progressed (Supplementary Figure S2).

The analysis of the main metabolic pathways in the host and the microbiome was visualized in IPTAH-V3.0 software in each stage of development of $L$. vannamei (Supplementary Figures S3-S5).

Enzymatic modules present in larvae in both the microbiome and the host were related to the degradation of xenobiotic compounds (Figure S3A), energy production (Figure S3B), fatty acid elongation (Figure S3D), secondary metabolism (Figure S3F), nucleotide (Figure S3I), amino acid metabolism (Figure S3K) and carbohydrate metabolism (Figure S3L).

The microbiome in larvae showed specific enzymatic modules associated with aromatic compounds degradation (Figure S3N), methanogenic carbon fixation (Figure S3M) and metabolism of terpenoids (carotenoid biosynthesis) (Figure S3E). The host transcripts in larval stages were associated with sucrose/starch metabolism.

In juvenile stages, shared metabolic modules were observed in both the host and the microbiome, which were associated with the degradation of aromatic compounds (Figure S4A), energy production (Figure S4B), steroid biosynthesis (Figure S4E), fatty acid elongation (Figure S4G), secondary metabolism (Figure S4H), biosynthesis of cofactor and vitamins (Figure S4J), nucleotide (Figure S4L), sulfur metabolism (Figure S4M), nitrogen metabolism (Figure S4P), biosynthesis of branched amino acids (Figure S4Q) and carbohydrate metabolism (Figure S4R).

Specific metabolic modules of the microbiome in juvenile stages, that participate in the fatty acid biosynthesis (Figure S4F), glycerolipid metabolism (Figure S4I) and galactose metabolism (Figure S4K), were observed. Furthermore, the presence of host specific modules, especially those related to the porphyrin and chlorophyll metabolism (Figure S4N) and the biosynthesis of phenolic compounds (flavonoids, flavonols) were detected.

Adult individuals of $L$. vannamei showed that several enzymatic modules were present in both host and the microbiome and were related to the fatty acids biosynthesis (Figure S5G), energy production (Figure S5H), prokaryotic carbon fixation (Figure S5I), nitrogen metabolism (Figure S5K), biosynthesis of branched amino acids (Figure S5M), nucleotide metabolism (Figure S5R), carbohydrate metabolism (Figure S5O,T,V), biosynthesis of cofactor and vitamins (Figure S5P,Q) and secondary metabolism (Figure S5W).

In the early stages of development (larvae and juveniles), the presence of enzymatic modules associated with glycan biosynthesis was observed (Figures S3G and S4J), specially those associated with the N-Glycan and O-glycan biosynthesis in juveniles.

As the development progressed, several eukaryotic enzymatic modules related to the photosynthetic carbon fixation (Figures S4C and S5E), biotin metabolism (Figures S4O and S5J), metabolism of branched amino acids, carotenoid biosynthesis (Figures S4E and S5M), bile acid production (Figures S4D and S5B), aromatic compound degradation (Figures S6A and S5A) and fatty acid degradation were present in adult and juvenile individuals.

The eukaryotic modules that belonged to the steroid hormone biosynthesis (Figures S3C, S4D and S5D) were present during all the developmental stages of L. vannamei.

\section{Discussion}

\subsection{Taxonomic Composition of the Active Microbial Communities in the Hepatopancreas of L. vannamei in Different Stages of Development}

The phylum level composition of the L. vannamei microbiome, throughout all the developmental stages showed high proportions of Proteobacteria, Actinobacteria, Firmicutes and Bacteroidetes. These phyla are considered cosmopolites, and have been reported previously to be present in the surrounding environment and in different types of samples $[10,15,30-37]$. The phyla composition is similar to those reported in the intestinal microbiome of other marine arthropods and shrimps $[10,16,38,39]$, which suggests that 
these phyla are involved in several digestive and other vital functions. The presence of the Gammaproteobacteria, Alphaproteobacteria and Betaproteobacteria classes was observed in high proportion in the present study and agrees with previous reports of the microbiome of marine organisms $[10,12,15,16]$. The presence of Flavobacteriaceae and Rhodobacteraceae throughout all the developmental stages of $L$. vannamei agrees with previous studies, where these families have been reported to be part of the core microbiome of L. vannamei $[2,3,8]$.

The role of the L. vannamei microbiome in primary metabolic processes could be associated with the nutrient uptake. It can be mentioned that the carbohydrate metabolism was present throughout all the developmental stages of L. vannamei. The carbohydrates were supplied in the commercial diet in the form of vegetable starches and fiber, the presence of these types of compounds have been reported to be able to influence the microbiome composition $[8,10,21]$ by the promotion of several bacterial classes (Methanococci, Actinobacteria, Bacilli), especially those that are able to generate extracellular enzymes capable of degrading complex carbohydrates [35-37,40-42]. These enzymes are capable of promoting biofilm production, which acts as a support network (physical and physiological) that could supply a series of digestible molecules in the hepatopancreas of L. vannamei throughout the development. These digestible molecules and metabolites produced by the microbiome could have an important role in development and adaptation processes, that could provide an advantage in adverse environmental conditions.

Regarding the protein uptake, they provided a high proportion of the nutritional formula, these are supplemented from different sources (plant, animal) and they are delivered in different amounts according to the developmental stage in peneids [43]. The use of proteins derived from plants could contain byproducts that could act as anti-nutritional factors (phenolic compounds, pigments), that could decrease the protein digestibility and weight gain during $L$. vannamei culture. Other processes related to the microbiome of $L$. vannamei were related with the vitamin B6 biosynthesis, in larvae (Figure S3J) and adult (Figure S5P), this type of process was reported previously in Rimicaris exoculata, where the bacterial classes Gammaproteobacteria and Epsilonproteobacteria participate in the biosynthesis of vitamins $[15,34]$. The endogenous biosynthesis of these types of compounds could be considered as a complementary source of vitamins and cofactors, that could enhance the resistance to biotic factors.

The high proportion of Gammaproteobacteria, Alphaproteobacteria and Betaproteobacteria has been reported previously in marine organisms, these bacterial classes participate in several metabolic processes $[10,12,15,16,34,35,44]$, such as: energy metabolism and carbon fixation (reductive TCA cycle), these functions could provide the host organism an advantage under environmental stress conditions present in culture ponds. In this sense, the presence of subsystems associated with stress response was observed in both the host and the microbiome, with an increasing tendency in L. vannamei, while in the microbiome it was observed in larvae and adult stages. These observations strongly suggest that under the culture process, stress conditions are occurring and the microbiome and L. vannamei are able to respond to the stress conditions in a joint manner in larvae and adult stages.

The presence of several different ubiquitous (Sphingomonadales, Xanthomonadales) and host specific (Vibrionales, Alteromonadales and Rhodobacterales) bacterial classes were detected in L. vannamei, which agrees with previous studies $[2,10,16,23]$. The presence of several of the Vibrionaceae, Lactobacillaceae, Bacillaceae and Pseudomonadaceae was observed throughout the development of L. vannamei. These bacterial families are considered as probiotic in marine organisms $[8,45]$. The culture conditions provided in the L. vannamei production promoted the growth of probiotic bacterial families, these types of organisms could provide the host organism with a series of nutritional factors, which in turn could confer to the host organism adaptive advantages to biotic and abiotic factors. In this sense, the presence of yeasts (larvae, juvenile) and yeast by-products (adult) as part of the commercial feed constituents, could provide the host organism with digestible molecules, the yeast cell components could act as elicitors, and the products of the yeast metabolism could modify the microbiome structure. 
Changes in the L. vannamei microbiome structure were observed in different stages of development, not only in the varying number of taxons but also in their proportion, which agrees with previous reports $[2,3,10,39]$. The changes in the microbiome are influenced by intrinsic factors of the host organism, environmental factors, lifestyle and nutrition [46,47]; due to the response capacity the microbiome composition is considered a reliable indicator for external changes. In this aspect the culture conditions of the aquaculture systems can promote the biomass formation of certain microbial groups $[9,10,15,21]$. Due the high amount of organic matter, the presence of, high molecular weight compounds, nitrogen and sulfur could reduce the microbial diversity when compared to wild-type systems. In this sense the presence of the nitrogen and carbohydrate metabolism was observed throughout all the developmental stages in the L. vannamei microbiome, while sulfur metabolism was present only in adult stages (Figure 6). These conditions could provide a suitable environment for the proliferation of several members of the phylum Proteobacteria.

Among the factors that could exert compositional changes in the microbiome, we could mention those present in the nutritional formula and the type of feed supplied during the culture. In the present study it could be observed that in juvenile stages the presence of the Comamonadaceae family, which was not present in larvae, this microbial family has been reported as part of the native microbiome of Artemia [2] and its presence coincides with changes in the composition of the commercial feeding formula, which was supplemented in juvenile stages with Artemia protein or this organism is supplied as live feed in the ponds at this particular stage of development.

\subsection{Functional Characterization of L. vannamei and Its Microbiome in Different Developmental Stages}

In the present study the presence of orthologous groups, subsystems and metabolic pathways related to the primary metabolism (metabolism of carbohydrates, proteins, lipids and energy production) were detected in both the host and the microbiome throughout all the developmental stages in L. vannamei which agrees with previous studies, where at least one-third of the genes associated with the primary metabolism are shared among all living organisms $[12,31,36,37,48]$. Among the functions present in both the microbiome and L. vannamei the "Carbohydrate metabolism" was highly represented in all the developmental stages. These compounds are supplied in the commercial feeding pellets in the form of fiber in different amounts in each developmental stage, other constituents provided in the feeding formula came from vegetable starches (larvae, juvenile, adult) and other grain by-products (adult). The metabolism of complex carbohydrates requires the joint action of the microbiome and the host in peneids $[9,10,37,44,49,50]$, this is reflected to a certain extent in adults where a similar proportion of transcripts in the host (9\%) and the microbiome $(10 \%)$ was observed. The carbohydrate supplementation could have diverse effects in several biological processes in arthropods, these compounds are used in processes of biosynthesis of the exoskeleton in arthropods and could influence the secondary metabolism [13,51]. In this regard, the presence of enzymatic modules associated with the metabolism of glycosaminoglycans in post-molted juveniles of L. vannamei (Figure S4J) is noted, where these type of carbohydrates are used in biosynthesis of chitin.

During the culture of L. vannamei it could be observed that the host and the microbiome, showed a high proportion of transcripts associated with the metabolism of proteins, throughout all the stages of development. The highest representation of the "Protein metabolism" subsystems was found in larvae and the "Amino acid metabolism" was found in juvenile stages. This type of response could be associated with the developmental stage and the protein presence supplemented in the commercial feed, which varied in dependence of the developmental stage. Previous studies in peneids mentions that the amount of protein and the quality could cause changes in the protein and amino acid profile $[37,52,53]$. In this aspect, changes in the amino acid processing could be associated with the protein source supplied. In larvae and adults the commercial feed contained animal and plant proteins, while in juvenile it not only had the aforementioned source but also included Artemia, which agrees with the presence of Comamonadaceae in the microbiome in this stage 
of development and with a sharp decrease in adults (Figure 4). These observations suggest that changes in the L. vannamei culture in juvenile and adult stages could include the addition of live feed in different proportions, which could be reflected in the microbiome composition and functional aspects of the amino acid metabolism.

Other supplied nutrients during the L. vannamei culture are lipids, vitamins and pigments. In the case of lipids, they are supplied in the commercial formula in the form of crude fat from different origins (fish oil, plant oils), which are present in different proportions in each stage of development. Previous studies mention that the lipids are supplied in the form of highly unsaturated fatty acids (fish), phospholipids and sterols (plants, algae) $[45,47]$. In the present study the lipid metabolism was observed in both host and microbiome, these types of compounds could act as signaling molecules, in the maintenance of the intestinal tissue and in the synthesis of steroid hormones in juvenile and adult stages where several of these metabolic modules were observed (Figures S3C, S4D and S5C) and are important in further stages of development, mainly in the gonadal development. The presence of the "Metabolism of Aromatic Compounds" subsystems in adult stages could be associated with the presence of plant origin compounds (pigments), which are used as additives in the aquaculture as immunostimulants [54].

The culture conditions played an important role in both the microbiome and the host, in larvae stages the "Biogenesis and Membrane Transport", "Replication" and "Transcription" subsystems were in high proportion These subsystems have been reported previously in processes of biomass generation in crustaceans $[9,10,30,38]$,. The presence of organic matter, nitrogen and sulfur in culture ponds provides an adequate environment for biomass generation. A low transcript representation could be noted in the host and the microbiome of metabolic processes related to "Transport and Catabolism", "Posttranslational modification, protein turnover and chaperones" and "Signal transduction". Previous studies performed in different species have shown that a high representation of these metabolic processes is found in environmental stress conditions $[32,40,55,56]$, the presence of chaperones and chaperonins have particularly been reported previously as stress markers given that their content increases under stress conditions [47]. The low proportion of these metabolic groups in L. vannamei and the microbiome suggests that the environmental variations during the culture of this species were present in a basal state which is common in non-stressed organisms.

The observed changes during the development of L. vannamei suggest that the culture conditions, feeding habits and the developmental stage are important factors that could shape the enzymatic activity and the microbiome composition. Previous metagenomic studies have shown that changes in the diet and the physiological conditions could alter the microbial composition, which may favor the inclusion of new microorganisms and promote different types of enzymatic activities $[3,10,12,13,22,34,37,42,53-57]$. The interaction between $L$. vannamei and its microbiome showed a strong connection with the feed changes, since the main predicted enzymatic modules and metabolic pathways were associated with the primary metabolism, in this sense the transcripts related to metabolic functions showed major changes in prokaryotes which corroborates that the microbiome is able to change its composition and function in response to physiological changes.

The presence of "Virulence, disease and defense" subsystems in the microbiome were observed in the microbiome throughout all the developmental stages in a low proportion, this agrees with previous studies where the presence of opportunistic pathogens is detected in healthy individuals at low concentrations [38-40]. The presence of opportunistic pathogens is promoted by the presence of several physiological factors present, like the concentration of organic material and nutrients provided during the L. vannamei culture. In order to cope with the infection a series of responses by the host were detected (Supplementary Table S2), which restricts the pathogenic movement (phagocytosis, apoptosis), cellular remodeling processes (tight junctions) and enzyme recruitment in sites of infection $[51,52,58-61]$. In this study the presence of metabolic modules related to the antibiotic metabolism in the host (streptomycin) and the biosynthesis of antibiotics 
(Ansamycins) in the microbiome, were observed in a low proportion in the L. vannamei culture. These results suggest that L. vannamei is able to control the pathogenic infection through a series of host mechanisms and the action of the microbiome through the production of antimicrobial agents.

The presence of the "Metabolism of Aromatic Compounds" subsystem was detected in both host and the microbiome, throughout all the developmental stages in a low proportion, these types of compounds could be found in the form of carotenoids, pigments and antioxidants [21,62-64], which are supplemented in the commercial feed. The low representation of these type of subsystem, suggest that these types of additives are provided in minor proportions when compared to other constituents of the feeding formula. It is worth mentioning that the presence of plant constituents of the formula could contain aromatics and other compounds that could be considered as anti-nutritional factors.

\section{Conclusions}

In this study, the microbiome function in different stages of development in L. vannamei could be observed, where changes in the structure of the microbiome were observed as the development progressed. Several classes and families of microorganisms with the ability to generate extracellular enzymes for the digestion and biosynthesis of molecules were observed, providing an adaptive advantage to the host organism.

The metabolic functions observed in this study required the joint action of the host and the microbiome throughout all the developmental stages, mainly in the primary metabolism, which was altered by the nutritional composition provided during L. vannamei culture, this process is of great importance because the changes in nutrition allow the inclusion of new enzymatic activities, influence developmental processes, maturation and the composition of the microbiome.

The microbiome requires a series of factors in order to perform all its functions for the host and the microorganisms, to form a network of metabolic support, known as "Quorum sensing", which is capable of supplying a series of compounds to the host organism and the microbiome which enhances adaptive capacity of the host.

In the present study it was possible to corroborate that the microbiome changes in terms of its composition and function, depending on different factors, such as development, nutrition and lifestyle. This is achieved by establishing a host-microbiome axis which involves a multidirectional communication between the metabolic pathways of the host and different microbial species. In this sense, we should consider the white shrimp Litopenaeus vannamei as a holobiont, an inseparable unit of eukaryotic and prokaryotic interactions. Future studies should consider the current findings, for the production of functional feed in shrimps and the microorganisms that inhabit them, promoting a better digestion and an improved health status. This vision, will promote the aquaculture being successful in terms of nutrition, growth, health and water quality. Further studies should be focused on the differential gene expression under environmental stress conditions, the joint response to pathogenic processes and the punctual study of the molting process and the gonadal development in L. vannamei.

Supplementary Materials: The following supporting information can be downloaded at: https: / / www.mdpi.com/article/10.3390/app12052483/s1, Figure S1: Functional classification based on level 2 orthologous groups in the microbiome during the development of L. vannamei; Figure S2: Functional classification based on level orthologous groups in the eukaryotic transcripts during the development of L. vannamei; Figure S3. Global metabolic pathway analysis in larval stages of $L$. vannamei; Figure S4. Global metabolic pathway analysis in juvenile stages of L. vannamei. Figure S5. Global metabolic pathway analysis in adult stages of L. vannamei. Table S1: Metabolic pathway analysis of the microbiome of L. vannamei in different stages of development using the KEGG orthology classification; Table S2: Metabolic pathway analysis of $L$. vannamei in different stages of development using the KEGG orthology classification. 


\begin{abstract}
Author Contributions: Methodology, J.E.A.-H., R.E.V.-G., B.Y.S.-G. and M.L.A.-O.; sequence processing and analysis, R.E.V.-G., B.Y.S.-G., J.E.A.-H. and M.L.A.-O.; functional analysis and data interpretation, R.E.V.-G., M.L.A.-O. and F.X.C.-C.; RNA quality control and sequencing, M.R.-D., R.E.V.-G. and M.L.A.-O.; writing-original draft preparation, R.E.V.-G. and M.L.A.-O.; formal analysis, F.X.C.-C.; resources, M.L.A.-O.; writing—review and editing, F.X.C.-C., M.R.-D. and B.Y.S.-G.; project administration, M.L.A.-O.; funding acquisition, M.L.A.-O. All authors have read and agreed to the published version of the manuscript.
\end{abstract}

Funding: This research was funded by the Mexico National Council of Science and Technology (CONACYT), through the National Problems grant (212745).

Institutional Review Board Statement: Not Applicable.

Informed Consent Statement: Not Applicable.

Data Availability Statement: The data are available upon request of the authors and a condensed version of the data are publicly available in the MG-RAST platform with the static link: https: / / www.mg-rast.org/linkin.cgi?project=mgp83086 (accessed on 8 December 2021).

Acknowledgments: To the General Direction of Academic Personal Affairs (DGAPA, UNAM) for the postdoctoral grant for REVG. To AquaPacific (Mazatlán, Sinaloa, Mexico) for providing access to their facilities and the assistance for the biological material collection.

Conflicts of Interest: The authors declare no conflict of interest.

\title{
References
}

1. Godinez-Siordia, D.E.; Chavez-Sanchez, M.C.; Gomez-Jiménez, S. Epicontinental Aquaculture of the Paciffic White Shrimp, Litopenaeus vannamei, (Boone, 1931). Trop. Subtrop. Agroecosyst. 2011, 14, 55-62.

2. Huang, Z.; Li, X.; Wang, L.; Shao, Z. Changes in the intestinal bacterial community during the growth of white shrimp, Litopenaeus vannamei. Aquacult. Res. 2014, 47, 1737-1746. [CrossRef]

3. Li, E.; Xu, C.; Wang, X.; Wang, S.; Zhao, Q.; Zhang, M.; Qin, J.G.; Chen, L. Gut Microbiota and its Modulation for Healthy Farming of Pacific White Shrimp Litopenaeus vannamei. Rev. Fish. Sci. Aquacult. 2018, 26, 381-399. [CrossRef]

4. $\quad$ Li, C.; Weng, S.; Chen, Y.; Yu, X.; Lu, L.; Zhang, H.; He, J.; Xu, X. Analysis of Litopenaeus vannamei Transcriptome Using the Next-Generation DNA Sequencing Technique. PLoS ONE 2012, 7, e47442. [CrossRef]

5. Tassanakajon, A.; Klinbunga, S.; Paunglarp, N.; Rimphanitchayakit, V.; Udomkit, A.; Jitrapakdee, S.; Sritunyalucksana, K.; Phongdara, A.; Pongsomboon, S.; Supungul, P.; et al. Penaeus monodon gene discovery project: The generation of an EST collection and establishment of a database. Gene 2006, 384, 104-112. [CrossRef]

6. Zeng, D.; Chen, X.; Xie, D.; Zhao, Y.; Yang, C.; Li, Y.; Ma, N.; Peng, M.; Yang, Q.; Liao, Z.; et al. Transcriptome Analysis of Pacific White Shrimp (Litopenaeus vannamei) Hepatopancreas in Response to Taura Sindrome Virus (TSV) Experimental Infection. PLoS ONE 2013, 8, e57515.

7. Food and Agriculture Organization of the United Nations (FAO). Global Aquaculture Production. Available online: http: //www.fao.org/fishery/statistics/en (accessed on 8 December 2021).

8. Cui, J.; Xiao, M.; Liu, M.; Wang, Z.; Liu, F.; Guo, L.; Meng, H.; Zhang, H.; Yang, J.; Deng, D.; et al. Coupling metagenomics with cultivation to select host-specific probiotic micro-organisms for subtropical aquaculture. J. Appl. Microbiol. 2017, 123, 1274-1285. [CrossRef]

9. Porchas-Cornejo, M.A.; Martínez-Porchas, M.; Vargas-Albores, F.; Gollas-Galvan, T.; Martínez-Córdova, L.R.; Vazquez-Euan, R.; Peña-Messina, E. High-resolution detection of bacterial profile of ocean water, before and after being used by shrimp farms. Aquacult. Int. 2017, 25, 1833-1843. [CrossRef]

10. Cornejo-Granados, F.; Gallardo-Becerra, L.; Leonardo-Reza, M.; Ochoa-Romo, J.P.; Ochoa-Leyva, A. A meta-analysis reveals the enviromental and host factors shaping the structure and function of shrimp microbiota. PeerJ 2018, 6, e5682. [CrossRef]

11. Heintz, C.; Mair, W. You Are What You Host: Microbiome Modulation of the Aging Process. Cell 2014, 156, 408-411. [CrossRef] [PubMed]

12. McFall-Ngai, M.; Hadfieldb, M.G.; Thomas, I.; Boschc, C.G.; Hannah, V.C.; Domazet-Loso, T.; Douglas, A.E.; Dubilierg, N.; Gerard, E.; Fukamii, T.; et al. Animals in a bacterial world, a new imperative for the life sciences. Proc. Natl. Acad. Sci USA 2013, 110, 3229-3236. [CrossRef] [PubMed]

13. Ezenwa, V.O.; Gerardo, N.M.; Inouye, D.W.; Medina, M.; Xavier, J.B. Animal Behavior and Microbiome. Science 2012, 338, 198-199. [CrossRef] [PubMed]

14. Hu, K.H.; Leung, P.C. Food digestion by cathepsin L and digestion-related rapid cell differentiation in shrimp hepatopancreas. Compar. Biochem. Physiol. Part B 2007, 146, 69-80. [CrossRef] 
15. Alcaide, M.; Tchigvintsev, A.; Martínez-Martínez, M.; Popovic, A.; Reva, O.N.; Lafraya, Á.; Bargiela, R.; Nechitaylo, T.Y.; Matesanz, R.; Cambon-Bonavita, M.A. Identification and characterization of carboxyl esterases of gill chamber-associated microbiota in the deep-sea shrimp Rimicaris exoculata by using functional metagenomics. Appl. Environ. Microbiol. 2015, 81, 2125-2136. [CrossRef] [PubMed]

16. Degli-Esposti, M.; Martinez-Romero, E. The functional microbiome of arthropods. PLoS ONE 2017, 12, e0176573. [CrossRef] [PubMed]

17. Dunn, M.F.; Ramírez-Trujillo, J.A.; Hernández-Lucas, I. Major roles of isocitrate lyase and malate synthase in bacterial and fungal pathogenesis. Microbiology 2009, 156, 3166-3175. [CrossRef] [PubMed]

18. Urich, T.; Lanzén, A.; Qi, J.; Huson, D.H.; Schleper, C.; Schuster, S. Simultaneous Assessment of Soil Microbial Community Structure and Function through Analysis of the Meta-Transcriptome. PLoS ONE 2008, 3, e2527. [CrossRef]

19. Wei, J.; Zhang, X.; Yu, Y.; Huang, H.; Li, F.; Xiang, J. Comparative Transcriptomic Characterization of the Early Development in Pacific White Shrimp Litopenaeus vannamei. PLoS ONE 2014, 9, e106201. [CrossRef] [PubMed]

20. Utiswannakul1, P.; Sangchai1, S.; Rengpipa, S. Enhanced growth of black tiger shrimp Penaeus monodon by dietary supplementation with Bacillus (BP11) as a probiotic. J. Aquatic. Res. Dev. 2011, 2, 006. [CrossRef]

21. Vargas-Albores, F.; Porchas-Cornejo, M.A.; Martínez-Porchas, M.; Villalpando-Canchola, E.; Gollas-Galván, T.; MartínezCórdova, L.R. Bacterial biota of shrimp intestine is significantly modified by the use of a probiotic mixture: A high throughput sequencing approach. Helgoland Mar. Res. 2017, 71, 5. [CrossRef]

22. Gamboa-Delgado, J.; Molina-Poveda, C.; Cahu, C. Digestive enzyme activity and food ingesta in juvenile shrimp Litopenaeus vannamei (Boone, 1931) as a function of body weight. Aquacult. Res. 2003, 34, 1403-1411. [CrossRef]

23. Tuyub-Tzuc, J.; Rendiz-Escalante, D.; Rojas-Herrera, R.; Gaxiola-Cortés, G.; Arena-Ortiz, L. Microbiota from Litopenaeus vannamei: Digestive tract microbial community of Pacific white shrimp (Litopenaeus vannamei). SpringerPlus 2014, 3, 280. [CrossRef] [PubMed]

24. Chen, X.; Zeng, D.; Chen, X.; Xie, D.; Zhao, Y.; Yang, C.; Li, Y.; Ma, N.; Li, M.; Yang, Q.; et al. Transcriptome Analysis of Litopenaeus vannamei in Response to White Spot Syndrome Virus Infection. PLoS ONE 2013, 8, e73218. [CrossRef]

25. Valle-Gough, R.E.; Apodaca-Hernández, J.E.; Rodriguez-Dorantes, M.; Arena-Ortiz, M.L. Metatrancriptomic analysis from the Hepatopancreas of adult white leg shrimp (Litopenaeus vannamei). Symbiosis 2018, 76, 51-62. [CrossRef]

26. Chomzcsinsky, P.; Sacchi, N. Single-step method for RNA isolation by acid guanidinium thyocyanate-phenol-chloroform extraction. Ann. Biochem. 1987, 162, 156-159. [CrossRef]

27. Müllhardt, C.; Beese, M.D. Fundamental Methods. In Molecular Biology and Genomics; Müllhadr, C., Beese, M.D., Eds.; Academic Press: Cambridge, MA, USA, 2007; pp. 11-36.

28. Keegan, K.P.; Glass, E.M.; Meyer, F. MG-RAST, a Metagenomics Service for Analysis of Microbial Community Structure and Function. Methods Mol. Biol. 2016, 1399, 207-233. [CrossRef] [PubMed]

29. Letunic, I.; Yamada, T.; Kanehisa, M.; Borg, P. IPath: Interactive exploration of biochemical pathways and networks. Trend Biochem. Sci. 2008, 33, 101-103. [CrossRef]

30. Aprill, A. Marine Animal Microbiomes: Toward Understanding Host-Microbiome Interaction in a Changing Ocean. Front. Marine Sci. 2017, 4, 222. [CrossRef]

31. Cao, X.H.; Schmutzer, T.; Scholz, U.; Pecinka, A.; Schubert, I.; Vu, G.T.H. Metatranscriptomic analysis reveals host-microbiome interactions in traps of carnivorous Genlisea species. Front. Microbiol. 2015, 6, 526. [CrossRef]

32. Costa, P.C.; Rei, M.P.; Ávila, M.P.; Leite, L.R.; De-Araujo, F.M.G.; Salim, A.C.M.; Oliveira, G.; Barbosa, F.; Chartone-Souza, E.; Nascimiento, A.M.A. Metagenome of a Microbial Community Inhabitating a Metal-Rich Tropical Stream Sediment. PLoS ONE 2015, 10, e0119465. [CrossRef]

33. Chan, K.G.; Ismail, Z. Tropical Soil Metagenome Library Reveals Complex Microbial Assemblage. bioRxiv 2015, 018895. [CrossRef]

34. Jan, C.; Petersen, J.M.; Werner, J.; Teeling, H.; Huang, S.; Glöckner, F.O.; Golyshina, O.V.; Dubilier, N.; Golyshin, P.N.; Jebbar, M.; et al. The gill chamber epibiosis of deep-sea shrimp Rimicaris exoculata: An in-depth metagenomic investigation and discovery of Zetaproteobacteria. Environ. Microbiol. 2014, 16, 2723-2738. [CrossRef] [PubMed]

35. Kanokatrana, P.; Uengwetwanit, T.; Rattanachomsri, U.; Bunterngsook, B.; Nimchua, T.; Tangphatsornruang, S.; Plengvidhya, V.; Champreda, V.; Eurwilaichitr, L. Insights into the Phylogeny and Metabolic Potential of a Primary Tropical Peat Swamp Forest Microbial Community by Metagenomic Analysis. Microb. Ecol. 2011, 61, 518-528. [CrossRef] [PubMed]

36. Koo, H.; Mojib, N.; Hakim, J.A.; Hawes, I.; Tanabe, Y.; Andersen, D.T.; Bej, A.K. Microbial Communities and Their Predicted Metabolic Functions in Growth Laminae of a Unique Large Conical Mat from Lake Untersee, East Antarctica. Front. Microbiol. 2017, 8, 1347. [CrossRef] [PubMed]

37. Tzeng, T.D.; Pao, Y.Y.; Chen, P.C.; Weng, F.C.H.; Jean, W.D.; Wang, D. Effects of host phylogeny and habitats on gut microbiomes of oriental river prawn (Macrobrachium nipponense). PLoS ONE 2015, 10, e0132860. [CrossRef]

38. Ding, Z.F.; Cao, M.J.; Zhu, X.S.; Xu, G.H.; Wang, R.L. Changes in the gut microbiome of the Chinese mitten crab (Eriocheir sinensis) in response to White spot syndrome virus (WSSV) infection. J. Fish. Dis. 2017, 40, 1561-1571. [CrossRef]

39. Xiong, J.; Dai, W.; Qiu, Q.; Zhu, J.; Li, C. Response to host-bacterial colonization in shrimp to developmental stage, environment and disease. Mol. Ecol. 2018, 27, 3686-3699. [CrossRef]

40. Frías-López, J.; Shi, Y.; Tyson, G.W.; Coleman, M.L.; Schuster, S.C.; Chrisholm, S.W.; De-Long, E. Microbial community gene expression in ocean Surface waters. Proceed. Natl. Acad. Sci. USA 2008, 15, 3805-3810. [CrossRef] 
41. Rejmánková, E.; Komárek, J.; Kormárkova, J. Cyanobacteria-A neglected component of biodiversity: Patterns of species diversity in inland marshes of northern Belize (Central America). Diversity Distrib. 2004, 10, 189-199. [CrossRef]

42. Zokaeifar, H.; Balcázar, J.L.; Saad, C.; Kamarudin, M.S.; Sijam, K.; Arshad, A.; Nejat, N. Effects of Bacillus subtilis on the growth performance, digestive enzymes, immune gene expression and disease resistance of white shrimp, Litopenaeus vannamei. Fish. Shellfish Immunol. 2012, 33, 683-689. [CrossRef]

43. Fox, J.M.; Davis, D.D.; Wilson, M.; Lawrence, A.L. Current Status of Amino Acid Requirement Research with Marine Penaeid Shrimp. In Advances in Aquaculture Nutrition VIII, Proceedings of the VIII International Symposium of Aquaculture Nutrition, Universidad Autónoma de Nuevo León, Monterrey, Nuevo León, México, 15-17 November 2006; Cruz-Suárez, L.E., Ricque-Marie, D., Salazar, M.T., Nieto-López, M.G., Villarreal-Cavazos, D.A., Puello-Cruz, A.C., García-Ortega, A., Eds.; Universidad Autónoma de Nuevo León: Monterrey, Mexico, 2006; pp. 182-196.

44. Booijink, C.C.G.M.; Boekhorst, J.; Zoetendal, E.G.; Smidt, H.; Kleerebezem, M.; de Vos, M. Metatranscriptome Analysis of the Human Fecal Microbiota Reveals Subject-Specific Expression Profiles, with Genes Encoding Proteins Involved in Carbohydrate Metabolism Being Dominantly Expressed. Appl. Environ. Microbiol. 2010, 76, 5533-5540. [CrossRef] [PubMed]

45. Ceseña, C.E.; Vega-Villasante, F.; Aguirre-Guzmán, G.; Luna-Gonzalez, A.; Campa-Cordova, A.I. Update on the use of yeast in shrimp aquaculture: A mini review. Int. J. Aquat. Res. 2021, 13, 1-16.

46. Nicholson, J.K.; Holmes, E.; Kinross, J.; Burcelin, R.; Gibson, G.; Jia, W.; Pettersson, S. Host-Gut Microbiota Metabolic Interactions. Science 2012, 336, 1262-1267. [CrossRef] [PubMed]

47. Michan, C.; Blasco, J.; Alhama, J. High-throughput molecular analyses of microbiome as tool to monitor the wellbeing of aquatic environments. Microbial Biotech. 2021, 14, 870-875. [CrossRef] [PubMed]

48. Franzosa, E.A.; Morgan, X.C.; Segata, N.; Waldron, L.; Reyes, J.; Earl, A.M.; Giannoukus, G.; Boylan, M.R.; Ciulla, D.; Gevers, D.; et al. Relating the metatranscriptome and metagenome of the human gut. Proceed. Natl. Acad. Sci. USA 2014, 111, E2329-E2338. [CrossRef]

49. Wongwilaiwalin, S.; Rattanachomsri, U.; Laothanachaeron, T.; Eurwilaichitr, L.; Igarashi, Y.; Champreda, V. Analysis of a thermophilic lignocellulose degrading microbial consortium and multi-species lignocellulolytic enzyme system. Enz. Microb. Technol. 2010, 47, 283-290. [CrossRef]

50. Xie, L.; Zhang, L.; Zhong, Y.; Liu, N.; Long, Y.; Wang, S.; Zhou, X.; Zhou, Z.; Huang, Y.; Wang, Q. Profiling the metatranscriptome of the protistan community in Coptotermes formosanus with emphasis on the lignocellulolytic system. Genomics 2010, 99, 246-255. [CrossRef]

51. Efianda, T.R.; Wahjuningrum, D.; Tarman, K.; Yuhana, M.; Effendi, I.; Saputra, F. Effects of Feed Supplementation of Nodulisporium sp. KT29 Induced by Vibrio harveyi Cells on Production Performance of Pacific white Shrimp Litopenaeus vannamei Cultured under Marine Culture System. Pak. J. Biotiechol. 2018, 15, 59-65.

52. D'Alvise, P.W.; Lillebo, S.; Prol-García, M.J.; Wergeland, H.I.; Nielsen, K.F.; Berg, O.; Gram, L. Phaeobacter gallaeciensis Reduces Vibrio anguillarum in Cultures of Microalgae and Rotifers, and Prevents Vibriosis in Cod Larvae. PLoS ONE 2012, 7, e43996. [CrossRef]

53. Neave, M.J.; Apprill, A.; Ferrier-Pagés, C.; Voolstra, C.R. Diversity and function of prevalent symbiotic marine bacteria in the genus Endozoicomonas. Appl. Microbiol. Biotechnol. 2016, 100, 8315-8324. [CrossRef]

54. Pan, C.H.; Chien, Y.H. Effects of dietary astaxanthin on body astaxanthin, growth, and survival of Penaeus monodon postlarvae. J. Fish. Soc. Taiwan 2004, 31, 269-280.

55. Bizans, J.E.; Macklaim, J.M.; Gloor, G.M.; Reid, G. Bacterial metatranscriptome analysis of a probiotic yogurt using a RNA-Seq approach. Int. Dairy J. 2014, 39, 284-292.

56. Leimenena, M.M.; Ramiro-Garcia, J.; Davids, M.; Van den Bogert, B.; Smidt, H.; Smid, J.E.; Boekhorst, J.; Zotendal, E.G.; Schaap, P.J.; Kleerebezem, M. A comprehensive metatranscriptome analysis pipeline and its validation using small intestine microbiota datasets. BMC Genom. 2013, 14, 530-543. [CrossRef] [PubMed]

57. Lowe, R.G.T.; Cassin, A.; Grandaubert, J.; Clark, B.L.; Van de Wouw, A.P.; Rouxel, T.; Howlett, B.H. Genomes and Transcriptomes of Partners in Plant-Fungal- Interactions between Canola (Brassica napus) and Two Leptosphaeria Species. PLoS ONE 2014, 9, e103098. [CrossRef] [PubMed]

58. Ji, P.F.; Yao, C.L.; Wan, Z.Y. Immune response and gene expression in shrimp (Litopenaeus vannamei) hemocytes and hepatopancreas against some pathogen-associated molecular patterns. Fish Shellfish Immunol. 2009, 27, 563-570. [CrossRef] [PubMed]

59. Soleimani, N.; Hoseinifar, S.H.; Merrifield, D.L.; Barati, M.; Abadi, Z.H. Dietary supplementation of fructooligosaccharide (FOS) improves the innate immune response, stress resistance, digestive enzyme activity and growth performance of Caspian roach (Rutilus rutilus) fry. Fish Shellfish Immunol. 2012, 32, 316-321. [CrossRef]

60. Ghaffari, N.; Sanchez-Flores, A.; Doon, R.; García-Orozco, K.D.; Chen, P.L.; Ochoa-Leyva, A.; López-Zavala, A.; Carrasco, S.; Hong, C.; Brieba, L.G.; et al. Novel transcriptome assembly and improved annotation of the white leg shrimp (Litopenaeus vannamei), a dominant crustacean in global seafood mariculture. Sci. Rep. 2014, 4, 1-10.

61. Robalino, J.; Almeida, J.S.; McKillen, D.; Colglazier, J.; Trent, H.F., III; Chen, Y.A.; Peck, M.E.; Browdy, C.L.; Chapman, R.W.; Warr, G.W.; et al. Insights into the immune transcriptome of the shrimp Litopenaeus vannamei: Tissue-specific expression profiles and transcriptomic responses to immune challenge. Physiol. Genom. 2007, 29, 44-56. [CrossRef] 
62. Pathak, S.C.; Ghosh, S.K.; Palanisamy, K. The Use of Chemicals in Aquaculture in India. In Use of Chemicals in Aquaculture in Asia, Proceedings of the Meeting on the Use of Chemicals in Aquaculture in Asia, Tigbauan, Iloilo, Philippines, 20-22 May 1996; Arthur, J.R., Lavilla-Pitogo, C.R., Subasinghe, R.P., Eds.; Aquaculture Department, Southeast Asian Fisheries Development Center: Tigbauan, Philippines, 2014; pp. 87-112.

63. Tsai, W.T. Current Status and Regulatory Aspects of Pesticides Considered to be Persistent Organic Pollutants (POPs) in Taiwan. Int. J. Environ. Res. Pub. Health 2010, 7, 3615-3627. [CrossRef] [PubMed]

64. Zimmer, M.; Danko, J.P.; Pennings, S.C.; Danford, A.R.; Ziegler, A.; Uglow, R.F.; Carefoot, T.H. Hepatopancreatic endosymbionts in coastal isopods (Crustacea: Isopoda), and their contribution to digestion. Mar. Biol. 2001, 138, 955-963. [CrossRef] 